\title{
Can ethnic humour appreciation be influenced by political reasons? A comparative study of the Basque Country and Calalonia
}

\author{
Carmelo Moreno del Río \\ University of Basque Country, Spain
}

\begin{abstract}
The aim of this paper is to compare the appreciation of humor that a sample of citizens in Spain has expressed about two different types of ethnic humor produced by two successful television programs from two autonomous communities in Spain: the Basque Country and Catalonia. Both regions are well-known in the Spanish society for their specific cultural and political features, which are seen as different from the rest of the country. To some extent, their particular character is fixed in the Spanish collective imaginary by some particular stereotypes, represented in stupidity and canniness jokes, following the model investigated by Christie Davies. In contrast to these jokes, the present study focuses on the ethnic humor circulated in these two regions, a kind of humor that is based on their specific identity and where it is possible to combine elements of self-deprecating humor and elements of aggressive humor towards Spain. More specifically, this work tries to test if the political background that these two regions represent in Spain-societies that dares the cohesion of the Spanish identity, even fighting for nationalist recognitions of political rights-could influence or not in the appreciation that the Spanish citizens as a whole have of this ethnic humor that Basques and Catalans produce.
\end{abstract}

Keywords: political humour, humour appreciation, ethnic humour.

\section{Introduction}

Spain is a country with some organizational and symbolic particularities. Politically, it is a federal system although this is not unanimously recognized. In terms of religious, it is a Catholic country although many people still consider that it is not Catholic enough and 
demand further policies to do so. In linguistic terms it has a language used by millions of people around the world (the Castilian Spanish is the common language of the whole country) although is multilingual in practice (several official languages coexist in 40 per cent of its territory). From the emotional point of view, Spain is well-known overseas for its mirth and its extroverted character, although internally many people would question the existence of a unitary "national style of humor", a quality that can serve, although not necessarily, as a useful thermometer for identifying the national character of a country (Ziv 1988; Davies 1990, 1998; Kuipers 2001; Davies 2002) [1]. The historical processes of "nation building" that took place in Spain in the $18^{\text {th }}$ and $19^{\text {th }}$ centuries aiming to attain the cohesion of Spanish society had a somewhat limited success, as shown in the data above. In fact, it is widely accepted that many of the problems Spain faced in the $20^{\text {th }}$ century, such as the civil war (1936-1939) and the dictatorship of Franco (1939-1975), could partly be explained by the failure of the centralizing project facing the resistance of the peripheral nationalist forces, and the failure of the modernizing project facing the conservative Catholic forces (Carr \& Fusi 1981; Preston 1986; Linz 1993; Preston 2012). Nowadays, Spain may be percieved as a "multinational nation", which is, to some extent, an incongruity in itself. Unfortunately, the efforts to deny this basic incongruence in Spanish national identity have often resulted in tragic, violent and conflictive responses, rather than in other less traumatic possibilities of social coexistence. Today the nationalist terrorism of ETA, which is on the point of disappearing in the Basque Country and Spain following decades of existence, is possibly the final grotesque expression of that always unsuccessful Spanish desire for national congruence.

With the establishment of the democratic system in 1975, a new stage opened in the history of Spain, which to some extent involved recognition of its multinational character for the first time. The most evident example of this situation is illustrated in the constitutional text passed in 1978, which established that Spain is a "nation" formed internally composed by different "nationalities". A first impression might invite one to think that this affirmation, which is highly ambiguous, juridically weak and technically illogical (how can there be one nation inside another?), is a recognition of failure, since it accepts the impossibility of attempting to definitively resolve the "nation building" project in Spain. The fact is, however, that the definition of Spain as a "nation of nations" has had many positive effects. Basically, it has left the door open to negotiation of its national identity, enabled a lot of tension to be released, and defused the national question. Besides, with respect to what concerns us here, it has made it possible for national identity to be seen as an incongruence one could be played with, that is, something that one can be treated in a more ludic and comic, rather than tragic, way.

It is no accidental that during the last years this phenomenon of playing comically with the incongruity of national identity in Spain has borne fruit in two regions, Catalonia and the Basque Country. These autonomous communities are where the highest levels of dual national identity are found, that is, they are where Spanish nationality coexists with a very strong regional national identity, expressed through nationalist movements and nationalist political parties that play a leading role not only in the political life of these communities but in Spanish politics in general (Díez Medrano 1995). It is precisely in the Catalan and Basque communities, where Spanish "nationalist incongruity" is intensely alive, some ethnic humor television programs have appeared on their respective regional channels in recent years. These programs have enjoyed great audience success, have high audience ratings for years, and have had a notable impact on public opinion in the two communities. These programs Vaya Semanita (What a Week) in the Basque Country and Polonia (Poland) in Catalonia- are based on sketches that narrate different everyday situations from social and political life, in which there is a play on the supposed incongruence of the respective overlapping national identities (Spanish vs. Basque; Spanish vs. Catalan) by mixing elements of self-mocking 
humor [2] with elements of aggressive humor [3] towards Spain (Kasmir 2002; Castello 2007). These programs, which are also familiar to audiences in other parts of Spain apart from their places of production, are interesting insofar as they represent a nwe and original phenomenon compared with the traditional humor about Catalans and Basques, who have always been considered only the butt of this kind of ethnic humor in Span. The shift is important and invites to analyse to what extent this kind of ethnic humor making fun at/with the Spanish national issue is appreciated.

The aim of this study is to study how this type of ethnic humor practiced in these two autonomous communities, the Basque Country and Catalonia, is appreciated in Spain as a whole and what discourses it gives rise to. In doing so, the content is organized into four sections. The first part briefly sets out the theoretical and conceptual framework on ethnic humor employed in this paper, inspired basically by the studies of Christie Davies, as well as by the results of other research studies on humor appreciation from the fields of sociology, psychology, and linguistics. In the second part we define the research questions, the field of work and the methodology employed to codify the information and interpret the data. The third part the main results obtained in the field work are presented. Finally, the fourth part is devoted to summarizing the conclusions and to posing new questions for future research.

\section{Are there valid theories for the study of humor?}

The work of Christie Davies is constructed from a position of a certain indifference towards even open rejection of- the main social theories existing on humor (Davies 1998a: 165; 2008: 157-158). Finding inspiration in such an anti-theoreticist author in order to lay down certain theoretical principles, as is the case here, requires some explanation. The starting point of his work is an interesting one. In his opinion, the problem with the great theories of humor in the social sciences, such as the functionalist theory and the conflict approach theory, lies in the fact that their object of study, humor, is so slippery and ambiguous that it ends up casting doubt on their proposals: the number of exceptions to their theoretical assertions is usually very high so that these theories finally end up making extravagant interpretations in order to justify themselves. Functionalist theories, which conceive of humor as a mechanism to alleviate tensions and favor social order, and conflict approach theories, which conceive of humor as a dialectical mechanism of aggression and social struggle, have difficulty in explaining practices as widespread as self-mocking humor -in our case study, the examples of Basque and Catalan ethnic humor are a perfect example of humor that largely involves Basques and Catalans laughing at themselves. Should we consider this type of humor as a kind of opium of the people imposed on Basques and Catalans to reaffirm stereotypes, as comic functionalism seems to suggest? Should we view it as a demonstration of collective masochism, of a self-resentment that Basques and Catalans feel about themselves, an act of aggression, as conflict theory consistently may accept? Trying to justify such arguments (Grotjahn 1987; Gruner 1997) so as to explain practices of humor that employ self-irony and self-mockery may be the consequence of the false attempt to attribute a social importance and effective relevance to humor that it lacks. Humor is neither so conservative as to create paranoid social control, nor is it so progressive as to provoke suicidal exorcisms. There is no evidence to support these ideas.

Criticism of such theories does not mean that we cannot construct models for analyzing humor. The real question concerns how to select the best perspective to understand the phenomenon of humor in a broad context. By studying the specific type of humor represented by canned jokes, Christie Davies has proposed a path -the method of comparing different societies and different ethnic groups producing the same kind of humor around the world- 
that leads to some significant results. The comparison of different modern contexts, no matter the particularities and specific outcomes, has enabled him to verify that ethnic humor built around jokes reproduces the same patterns in different modern societies: generally ethnic jokes are organized around a center-periphery scheme according to which the center is made up with the social majority (which defines in each country the limits of the coherence, the boundaries of norms and the mainstream social values), while the periphery is formed by social minorities (which are defined as extravagant with respect to the majority, that is, as incongruent and comic from the perspective of the mainstream position). Both ethnic majorities and minorities have to some extent a fixed place in ethnic humor: generally it is the minorities, and not the social majorities, who are the main butt of ethnic jokes. However, and this is significant, both majority and ethnic minorities are conscious producers of this kind of humor about the same ethnic group. Moreover, the minority targeted in ethnic jokes can adopt two comic versions with respect to the majority: the deficit version -stupidity- and the excess version -cunning. This means that the key concept to understand ethnic humor is not about functionality of conflict but the management of incongruity with regard to the mainstream normality: the management of disproportionate stupidity or cunning, which are embodied in a supposed minority, in opposition to what the majority in a specific society considers normal [4]. Obviously, social ethnic minorities can be of many types and the type of ethnic humor created by and around them can also exhibit numerous variants. Thus, as Davies explains in his comparative analysis of the two ethnic groups best known internationally as protagonists of so-called canny jokes, the Scottish and the Jews, the former tend to employ self-mocking humor without reference to any external group, while the latter make a much more balanced use of self-mocking humor towards their own ethnic group and aggressive humor mocking other social groups in comparison to themselves (Davies 2002: 17-76).

There are three reasons why the model of comparative analysis employed by Davies is important for this study. Firstly, it provides a good explanation of the center-periphery dimension applied to ethnic humor that fully coincides with what occurs in Spain. The fact that certain peripheral groups like the Catalans and Basques are the butt of this type of joke is not a "Spanish eccentricity", but the same pattern that is reproduced in other contexts, in other modern societies. In this sense, the use of Basques and Catalans in the scripts of ethnic humor in Spain could be understood as a common way Spaniards (and, among them, Basques and Catalans) have to manage their own national incongruities and transform them into comic material. In this respect, the absence of something that we could call "Spanish humor that laughs at what is ethnically Spanish" should not be seen as an anomaly, but as a constant that is repeated in practically most countries: to state this clearly, majority ethnic groups do not practice humor about themselves but about the others, because, amongst other reasons, nowhere does the social majority of a community feel itself to be a comic incongruence. Secondly, Davies' model stresses the importance held by the peripheral ethnic groups due to their ability to be not only the butt but also the producers of ethnic humor. In this sense, it comes as no surprise that Catalans and Basques should be the two main producers of ethnic humor in Spain [5]. Both social groups, insofar as there is a certain tension in their relation with Spanish national identity, have many more possibilities for producing a type of ethnic humor that basically refers to themselves and to the supposed incongruence of their relation to the national identity of the social majority, i.e. the Spanish in general. It is not a sufficient condition, since not all peripheral groups in this situation produce ethnic humor, but it seems to be a necessary one. Finally, in the third place, Davies' model provides an explanation about the broad variability of ethnic humor that can be produced by peripheral ethnic groups. Unlike the ethnic humor made by social majorities, usually targeting minorities, the fact that the ethnic humor of a minority can be more self-mocking (the "Scottish" model) or more balanced (the "Jewish" model) indicates that there is a certain difference in the forms and 
contents of this type of humor that might be important not only in its production but also in its appreciation (Davies 2002: 17-75).

Following the terminology employed by Davies, the cases of Catalan and Basque ethnic humor that we shall be analyzing here are somewhat special. On the one hand, they clearly represent (a) humor realized by cunny groups in relation to a larger population (the Spanish population). But, on the other hand, this type of humor made in their own regional televisions represents (b) humor realized for an audience formed by a social majority (the Basques and Catalans in their respective territories) that practice humor at the expense of other social minorities (those considered to be Spanish living in these communities, who in a certain way represent the Spanish as a whole). This double dimension allows for the use of a large variety of devices, not only features of self-mocking humor but also some aggressive humor towards the Spanish: Catalan and Basque humor laughs at themselves, but at the same time enjoy making fun at their incongruous relation with the rest of Spaniards. In my opinion, the variety of these options of ethnic humor is significant, especially when the recipients of this humor are the Spanish, the ethnic group that is not normally the butt of the ethnic humor practiced in Spain.

Having reached this point, just to achieve the goals of the paper, we believe that the model proposed by Davies can be complemented with other useful approaches to measure the different responses in the appreciation of this ethnic humor. The relatively limited importance that Davies attached to an empirical approach of humor appreciation is due to his being mainly interested in showing the plurality of ethnic humor-tellers. However, we believe that in the present study the plurality of responses in the reception of ethnic humor is also important. As shown by numerous humor scholars measuring the appreciation of humor at both the social and individual levels, humoristic practices are appreciated differently. This depends not only on their form -the differences of appreciation, for example, between resolved and unresolved incongruent humor- (Raskin 1985; Attardo \& Raskin 1991; Ruch et al. 1991; Attardo 1994; Ruch 1992, 1996; Ruch \& Forabosco 1996) but also on their content, that is, who are the possible butt of these practices (Martin et al. 2003; Ford and Ferguson 2004; Martin 2007; Ferguson and Ford 2008; Kuipers 2008). In this respect, the basic distinction drawn by Davies between self-mocking humor (the "Scottish" model) and humor that is more balanced between self-mockery and mocking third parties (the "Jewish" model) is a good starting point. But we are going to widen this comparison with the inclusion of a third option: the "aggressive" character that can be perceived in the ethnic humor of a peripheral group. In our case, we believe that the discourses of Spanish citizens explaining their appreciation of the type of humor produced by Catalans and Basques can show these three variations, which are comparable as ideal-types of humor appreciation. These three ideal-types would let us to distinguish the humor appreciation of the participants if their attention are focused on the form (balanced humor) in which the sketches are constructed or if their attention are focused on the content (aggressive or self-mocking humor) of the social groups that are the direct butt of these humoristic practices. For example, let us imagine three people watching the same sketch produced by the Catalan television program Polonia and stating the following three different comments: (i) "I like it because the incongruities presented are funny and the performance of the actors is good"; (ii) "I like it because it shows the way someone like the Catalans can make fun of themselves"; (iii) "I like it because some extreme Spanish stereotypes are well-ridiculed". Although it looks like these three people are watching the same sketch, in fact they focused their attention in different ways.

The following section details the hypotheses of this research, the methodology employed to obtain the material for analysis, and the codification of this information to compare the different appreciations of the ethnic humor of Catalans and Basques. 


\section{Hypotheses, methodology and data collection}

The first hypothesis in this study is that the appreciation of ethnic humor produced in the periphery (in this case Catalonia and the Basque Country) differs depending on the relationship of each of these two peripheries with the center $(\mathrm{H} 1)$. Given that the center, namely the ethnic majority in Spain, could produce aggressive but not self-mocking humor, we suppose that the greater appreciation of self-mocking elements and the lower appreciation of aggressive elements in Catalan and Basque ethnic humor imply a greater enjoyment of this humor. To some extent, the people of the center really enjoy the humor of these groups when they behave as peripheral groups and not as groups with pretensions to centrality.

The second hypothesis posits that the appreciation of the ethnic humor produced in the periphery (in this case the Basque Country and Catalonia) differs depending on the relationship that each of these two peripheries has with the other peripheries in Spain (H2). Spain has different types of peripheral ethnic groups, with greater and lesser levels of dual national identity, which also vary according to their greater or lesser geographical proximity to the Basques and Catalans. Besides, some of the peripheral ethnic groups are known for their peripheral style of ethnic humor (basically the Andalusians and Canary Islanders in the south of Spain, and the Aragonese and Galicians in the north), and potentially also have a different relationship both with Spain and with the Basque Country and Catalonia. We believe that these peripheral ethnic groups with a peripheral style of ethnic humor could be more favorably disposed to appreciating and enjoy the ethnic humor of Catalans and Basques than people from the center.

Finally, the third hypothesis suggests that the appreciation of peripheral ethnic humor (in this case from the Basque Country and Catalonia) could show more social and political cohesion in Spain if the citizens focus their attention on the formal dimension of humor-that $i s$, the balanced humor- instead of emphasizing the content dimension of humor, both aggressive and self-mocking (H3). We believe the citizens of Spain in general could better enjoy the ethnic humor produced by Catalans and Basques if their appreciation was directed not so much to the specific allusions to a particular ethnic group or concrete issue, but to the elements that form the structure of the audiovisual humorous practice: the script, the staging, the sophistication of the elements that shape the play of incongruity, the cognitive pleasure involved in resolving an incongruity or in finding an absence of resolution, and in identifying the character of the issues dealt with beyond their ethnic particularity. In this case we would be facing the equivalent of what Davies calls balanced humor [6], a humor that transcends specific references to any particular ethnic group because it speaks comically of values and forms that everyone in a society as the Spanish one can understand and enjoy.

To test the hypothesis data was collected from ten focus groups held in nine Spanish cities [7]. In selecting the ten groups the following questions were considered: the importance of the territorial variable (peripheral vs. central autonomous communities: 7-2) (autonomous communities of the north, center and south: 4-3-2); the existence of programs of ethnic humor in regional televisions (yes vs. no: 5-4); communities close to and distant from Catalonia and the Basque Country. A control group was formed that differed from the rest as it was formed of Spanish immigrants in one of the two autonomous communities of the study (Catalonia), unlike the rest of the groups, which were more ethnically homogenous. Similarly, the following variables were controlled: age (excluding people under 25 and over 55), sex (equal representation) and level of education (excluding people with a low level) to avoid a dispersion of opinion that would contaminate the possible effect of the main variable, which was territorial.

The aim of the focus groups was to detect discourses and arguments concerning a series of eight videos of ethnic humor from different autonomous and national programs, which 
included a video from the program Vaya semanita (the Basque Country) and another from the program Polonia (Catalonia) [8]. The two videos refer to both ethnic and political questions, relating to certain characteristic features about the personality of the two social groups that are recognizable to Spanish public opinion. The screenplay is organized around two public policies. In the Basque case, a research policy carried out by the Basque government that showed to what an unsuspected (incongruous) extent all the problems experienced in the Basque Country are the fault of the Spanish central government. In the Catalan case, it is about an educational policy calling for the possibility of studying the Catalan language in all of Spain, and whose implementation (incongruously) backfires on the image of Catalonia. In both sketches there were elements of aggressive humor (towards the bad Spanish influence on the Basque lifestyle, towards Spanish rejection of Catalan language), elements of selfmocking humor (about Basque personality, about Catalan culture) and elements of balanced humor (scripts, wordplays, overlapping images and performances used in both sketches just to make fun beyond references of a particular ethnic group).

The focus groups were developed through a narrow-structured plot with predetermined topics for discussion and supported by two questionnaires that the participants filled in while they watched the sketches. Amongst the issues dealt with in the focus groups there were several topics such as the following: the degree of familiarity with each video, the level of appreciation, the opinions about the sophistication and aggressiveness of the sketches, their level of political intentionality detected by the participants, and an explanation of the reasons why these videos might or might not be pleasing both at an individual level and in the different autonomous communities, and even at the level of Spain in general. The information collected from the questionnaires was codified on a data set (DS1) with the unit of analysis being each of the participants in the ten groups (a total of 80 units). The information collected from the transcriptions of the groups was codified on another data set (DS2), with the unit of analysis being each of the interventions of the 80 participants in the ten groups (a total of 8,600 units). In this second data set a series of variables were added following the theoretical design of the study that we saw above: variables that measure the appreciation of the humor (positive/neutral/negative) [9], the sense of humor orientating each intervention (balanced/aggressive/self-mocking humor) [10], two variables on ethnic mentions (yes/no) (ethnic group mentioned) and another on political mentions (yes/no). The a posteriori codification of these variables in this second data set was done by three people [11], working independently, and the degree of initial agreement, 85 per cent, was refined until total consensus was reached on the codification of the final result.

\section{Basque and Catalan humor in Spain. Results}

The first approach to determining the appreciation of the Catalan and Basque humor sketches used in our study is summarized in table 1, which reflects four levels of evaluation: the participants' personal evaluation of the sketches; the appreciation that would in their opinion be made by the people of their autonomous community; the degree of success of these sketches in Spain as a whole; and, finally, the degree of political intentionality participants detected in each sketch.

In general, the evaluation of the two sketches is apparently similar at a personal level (evaluation and degree of political intentionality) but different when it comes to projecting the regional and national evaluation of such sketches. In the Catalan case, the average is 4.34 points over a total of 7 and its political intentionality is 2.54 points over a total of 3 . In the Basque case, the average evaluation is a little less (4.24 points) and perceived political intention is also lower (2.11). If we compare the Basques and Catalans with the rest of the 
groups, it seems that the two peripheral groups evaluate the sketches above the average although their perception of political intentionality is a little different: the Catalans see less political intentionality in the sketches than the majority, while the Basque see more intentionality. Finally, however, the greatest difference is observed in the perception of the success of the two sketches in Spain: it seems that the majority of the groups are of the opinion that the humor proceeding from the Catalan sketch would not be successful in Spain something that the Catalans and Basques agree with-while in the case of the Basque sketch the great majority of the groups think that it would be a success, including the group of Basques. The only groups that emphatically assert that this type of Basque and Catalan humor would not be successful in their region or in Spain are the Andalusians (SEV) and the Canary Islanders (LZR): two communities from the south of Spain with their own ethnic humor and whose humoristic character is possibly different from that of Catalonia and the Basque Country, located in the north of the country. In the rest of the regions we would need greater precision to know what the differences in the appreciation of the success (or failure) of Basque and Catalan humor in Spain are based on.

Table 1. Appreciation of Catalan and Basque Sketches by Spanish regional focus groups

\begin{tabular}{|c|c|c|c|c|c|c|c|c|c|c|c|}
\hline & \multirow{2}{*}{$\begin{array}{l}\text { SPAIN } \\
\text { Mean }\end{array}$} & \multicolumn{10}{|c|}{ FOCUS GROUPS } \\
\hline & & BIO & SEV & MAD & BCN1 & BCN2 & VLN & ZAR & LZR & VLD & ACÑ \\
\hline Catalan Skt: EVALUATION & $\begin{array}{r}\text { IVIean } \\
4.34\end{array}$ & $\begin{array}{r}\text { IVIean } \\
4.75\end{array}$ & $\begin{array}{r}\text { IViean } \\
4.13\end{array}$ & $\begin{array}{r}\text { IVlean } \\
3.83\end{array}$ & $\begin{array}{r}\text { IVlean } \\
6.00\end{array}$ & $\begin{array}{r}\text { Mean } \\
4.44\end{array}$ & $\begin{array}{r}\text { Mean } \\
2.75\end{array}$ & $\begin{array}{r}\text { Mean } \\
4.00\end{array}$ & $\begin{array}{r}\text { Mean } \\
5.00\end{array}$ & $\begin{array}{r}\text { Mean } \\
2.71\end{array}$ & $\begin{array}{r}\text { Mean } \\
5.25\end{array}$ \\
\hline Catalan Skt: ENJOYED YOUR REGION > SPAIN & .05 & .13 & -.38 & -.33 & 1.00 & .78 & .25 & -.13 & -.25 & -.57 & -.38 \\
\hline Catalan Skt: SUCCEED IN SPAIN & -.27 & -.25 & -.13 & .00 & -.78 & -.22 & -.75 & -.38 & -.38 & -.14 & .38 \\
\hline Catalan Skt: POLITICAL INTENTIONALITY & 2.54 & 2.75 & 2.38 & 3.00 & 2.00 & 2.44 & 2.75 & 2.63 & 2.75 & 2.43 & 2.50 \\
\hline Basque Skt: EVALUATION & 4.24 & 5.13 & 2.88 & 4.00 & 4.56 & 4.44 & 3.63 & 4.00 & 4.38 & 4.71 & 4.63 \\
\hline Basque Skt: ENJOYED YOUR REGION > SPAIN & .06 & .75 & -.38 & .17 & .56 & -.11 & .00 & -.25 & -.38 & .57 & -.25 \\
\hline Basque Skt: SUCCEED IN SPAIN & .17 & .50 & -.25 & .17 & -.11 & .22 & .00 & .38 & -.13 & .71 & .25 \\
\hline Basque Skt: POLITICAL INTENTIONALITY & 2.11 & 2.63 & 2.75 & 2.33 & 2.00 & 1.78 & 1.88 & 2.00 & 2.00 & 1.71 & 2.13 \\
\hline
\end{tabular}

Evaluation (range from 0 to 7); Enjoyed in your region more than in the rest of Spain (range from -1 to 1); Succeed in Spain (range from -1 to 1); Political Intentionality (range from 0 to 3 ). Source: DS1.

In this respect, table 2 is interesting because it enables us to observe the difference of appreciation in the evaluation of Catalan and Basque humor in Spain according to the three ideal-types of humor that we have introduced in our codification (balanced humor, aggressive humor and self-mocking humor). Here the differences between Catalan humor and Basque humor begin to emerge more clearly.

In the case of the Catalan sketch, there is a notably high percentage (34.4) of interventions in the groups indicating that this ethnic humor is balanced and positive. The arguments used are that the Catalan sketch is sophisticated -in fact, nearly all the groups indicated that this sketch was the most sophisticated of the eight videos shown, the acting was amusing, the sketch was well elaborated, the plot introduced many comic incongruences and it was, in short, well performed. Also notable, however, is the high percentage (27.5) of interventions indicating that the Catalan sketch is negatively aggressive -that is, others are laughed at in an unpleasant way- compared with a smaller group of interventions (18.3) that indicate that the Catalan sketch introduces features of positive self-mocking humor -that is, they know how to make fun of themselves. If we analyze the data by focus groups, two clusters emerge clearly. On one side, the cluster of the Andalusians (SEV), people from Madrid (MAD), the Valencians (VLN), the Aragonese (ZAR) and the Castilians (VLD): all consider that the Catalan sketch uses negatively aggressive humor to a greater extent, although in the case of Valencians (VLN) and Aragonese (ZAR), which are communities that 
border on Catalonia, the negative and positive interventions are somewhat more balanced. The other cluster is formed by Basques (BIO), Canary Islanders (LZR) and Galicians (ACÑ), besides the Catalans themselves, both natives (BCN1) and Spanish immigrants to Catalonia (BCN2), who emphasize the positive character of the Catalan sketch: it is balanced in form and basically self-mocking in content.

Table 2. Type of humor of Catalan and Basque Sketches by Spanish regional focus groups

\begin{tabular}{|c|c|c|c|c|c|c|c|c|c|c|c|}
\hline & \multirow[b]{2}{*}{ SPAIN } & \multicolumn{10}{|c|}{ FOCUS GROUPS } \\
\hline & & BIO & SEV & MAD & BCN1 & BCN2 & VLN & ZAR & LZR & VLD & $A C \tilde{N}$ \\
\hline & $\%$ & $\%$ & $\%$ & $\%$ & $\%$ & $\%$ & $\%$ & $\%$ & $\%$ & $\%$ & $\%$ \\
\hline Catalan Skt: Balanced Humor (-) & 2.2 & 0.0 & 2.1 & 0.0 & 1.5 & 0.0 & 0.0 & 0.0 & 0.0 & 11.9 & 7.3 \\
\hline Catalan Skt: Balanced Humor (n) & 1.1 & 0.0 & 6.4 & 0.0 & 0.7 & 0.0 & 0.0 & 0.0 & 3.7 & 0.0 & 0.0 \\
\hline Catalan Skt: Balanced Humor (+) & 34.4 & 43.5 & 12.8 & 23.7 & 28.4 & 52.6 & 11.8 & 55.0 & 51.9 & 21.4 & 50.9 \\
\hline Catalan Skt: Aggressive Humor (-) & 27.5 & 0.0 & 46.8 & 71.1 & 8.2 & 29.8 & 37.3 & 40.0 & 16.7 & 59.5 & 5.5 \\
\hline Catalan Skt: Aggressive Humor (n) & 1.1 & 0.0 & 4.3 & 0.0 & 0.7 & 1.8 & 0.0 & 0.0 & 3.7 & 0.0 & 0.0 \\
\hline Catalan Skt: Aggressive Humor (+) & 9.6 & 43.5 & 8.5 & 5.3 & 5.2 & 1.8 & 11.8 & 5.0 & 20.4 & 4.8 & 12.7 \\
\hline Catalan Skt: Self-Mocking Humor (-) & 4.1 & 0.0 & 0.0 & 0.0 & 9.0 & 0.0 & 15.7 & 0.0 & 0.0 & 0.0 & 3.6 \\
\hline Catalan Skt: Self-Mocking Humor (n) & 1.7 & 0.0 & 2.1 & 0.0 & 6.0 & 0.0 & 0.0 & 0.0 & 0.0 & 0.0 & 0.0 \\
\hline Catalan Skt: Self-Mocking Humor (+) & 18.3 & 13.0 & 17.0 & 0.0 & 40.3 & 14.0 & 23.5 & 0.0 & 3.7 & 2.4 & 20.0 \\
\hline CATALAN Skt: Positives - Negatives & 28.5 & 100.0 & -10.6 & -42.1 & 55.2 & 38.6 & -5.9 & 20.0 & 59.3 & -42.9 & 67.3 \\
\hline Basque Skt: Balanced Humor (-) & 8.8 & 2.9 & 9.9 & 6.1 & 0.0 & 9.1 & 44.2 & 4.3 & 2.9 & 6.3 & 15.8 \\
\hline Basque Skt: Balanced Humor (n) & 1.7 & 1.9 & 1.4 & 0.0 & 0.0 & 9.1 & 0.0 & 3.4 & 0.0 & 0.0 & 0.0 \\
\hline Basque Skt: Balanced Humor (+) & 21.4 & 14.3 & 11.3 & 27.3 & 16.3 & 27.3 & 16.3 & 19.8 & 23.5 & 34.4 & 35.1 \\
\hline Basque Skt: Aggressive Humor (-) & 16.5 & 1.0 & 45.1 & 21.2 & 2.3 & 12.1 & 7.0 & 29.3 & 20.6 & 12.5 & 3.5 \\
\hline Basque Skt: Aggressive Humor (n) & 0.8 & 0.0 & 1.4 & 0.0 & 4.7 & 0.0 & 2.3 & 0.9 & 0.0 & 0.0 & 0.0 \\
\hline Basque Skt: Aggressive Humor (+) & 6.8 & 6.7 & 7.0 & 9.1 & 11.6 & 0.0 & 0.0 & 9.5 & 2.9 & 3.1 & 12.3 \\
\hline Basque Skt: Self-Mocking Humor (-) & 2.7 & 5.7 & 0.0 & 3.0 & 2.3 & 3.0 & 16.3 & 0.0 & 0.0 & 0.0 & 0.0 \\
\hline Basque Skt: Self-Mocking Humor (n) & 0.3 & 0.0 & 0.0 & 0.0 & 4.7 & 0.0 & 0.0 & 0.0 & 0.0 & 0.0 & 0.0 \\
\hline Basque Skt: Self-Mocking Humor (+) & 40.9 & 67.6 & 23.9 & 33.3 & 58.1 & 39.4 & 14.0 & 32.8 & 50.0 & 43.8 & 33.3 \\
\hline BASQUE Skt: Positives - Negatives & 41.1 & 79.0 & -12.7 & 39.4 & 81.4 & 42.4 & -37.2 & 28.4 & 52.9 & 62.5 & 61.4 \\
\hline
\end{tabular}

Source: DS2.

In the case of the Basque sketch, however, the situation is totally different. The option of selfmocking humor (40.9) is the highest in nearly all the groups, and the number of interventions referring to the use of positive balanced humor, i.e. that appreciate the sketch's humor in formal terms, is also high (21.4) -it receives the second best evaluation of the eight in terms of sophistication, although at a certain distance from the Catalan sketch (34.4). Only the Andalusians (SEV) and the Valencians (VLN) stand out from the rest of the groups in the opposite direction. In the case of Andalusians, the negatively aggressive character of the sketch stands out (45.1), as well as its being formally boring (9.9), although a significant percentage of the interventions (23.9) positively recognize the self-mocking aspect of Basque humor. In the case of the Valencians, on the contrary, the negative character is general and emphatic: they do not like the sketch's form because it is boring (44.2) and they also consider the self-mocking focus in the sketch's humor negatively (16.3 per cent of the interventions), which is something that also emerges in their comments on the Catalan sketch (15.7 per cent of the interventions). This can perhaps be explained because the Valencians (VLN) are the only peripheral group in the whole sample that does not have any successful ethnic humor programs on their regional television.

In summary, both sketches receive more positive evaluations (Catalans: 62.3; Basques: 69.1) than negative (33.8 and 28.0) but the balance is greater in the Basque case $(+41.1$ points) than in the Catalan case ( +28.3 points). Besides, the appreciation of the Basque sketch is notable due to its self-mocking character while the Catalan sketch is notable due to its 
balanced character. They stand for two different forms of appreciating peripheral ethnic humor: at the individual level the participants give a little more emphasis to the Catalan sketch over the Basque sketch, but their opinions change when they project their opinions at the social level. In this respect, regarding the first working hypothesis, we suggest that the high appreciation of negative aggressive humor in the Catalan sketch, unlike the high appreciation of positive self-mocking humor in the Basque sketch, means that the opinions of the participants are not only different but asymmetrical. We could argue that the Basque sketch comes closer than the Catalan sketch to meeting the conditions that the participants in the groups expect and easily accept as desirable in peripheral ethnic humor, as it employs a type of humor that is perfectly compatible with the humoristic position of the center. The two groups most clearly representative of the center where there is no regional ethnic humor -the group of people from Madrid (MAD) and the Castilian group (VLD)- confirm this: in both cases the Basque sketch was well appreciated formally and substantively, insofar as the butt of the humor is the peripheral group itself, while in the Catalan sketch the formal appreciation is lower and substantively the target of the humor is not the peripheral group itself but the others, that is, the Spanish.

The second hypothesis explores to what extent the different peripheral regions in Spain could exhibit different humor appreciation of the Catalan and Basque sketches. We have seen that the participants in the different regions appreciate both sketches formally, although the appreciation of the content varies from case to case. If we now compare the results according to the greater or lesser geographical distance of the groups' participants from Catalonia and the Basque Country, as shown in table 3, the results are interesting, even surprising. We take it for granted that the native residents of Catalonia and the Basque Country are familiar with, and offer a higher evaluation of, their respective sketches than the rest of the participants. However, their opinions change radically when asked about the possibilities of the sketch succeeding in Spain and its degree of political intentionality. The Catalans consider that their sketch has less political intentionality (2.10) than the majority of the participants think, but in spite of that they do not believe it would be successful in Spain (0.20). On the contrary, the Basques consider that their sketch has more political intentionality than the majority of the participants think, but in spite of that they believe it would be successful in Spain (0.71) to the same degree as the rest of the participants.

Table 3. Appreciation of Catalan and Basque Sketches by proximity to Catalonia and the Basque Country of regional focus groups

\begin{tabular}{|c|c|c|c|c|}
\hline & \multirow[b]{2}{*}{$\begin{array}{l}\text { SPAIN } \\
\text { Mean }\end{array}$} & \multicolumn{3}{|c|}{ PROXIMITY OF THE PARTICIPANTS } \\
\hline & & $\begin{array}{r}\text { Distant } \\
\text { Mean }\end{array}$ & $\begin{array}{l}\text { Close } \\
\text { Mean }\end{array}$ & $\begin{array}{r}\text { Native } \\
\text { Mean }\end{array}$ \\
\hline Catalan Skt: KNOWLEDGE & .41 & .27 & .40 & 1.00 \\
\hline Catalan Skt: EVALUATION & 4.34 & 4.30 & 3.76 & 6.00 \\
\hline Catalan Skt: ENJOYED YOUR REGION > SPAIN & .05 & -.30 & .32 & .90 \\
\hline Catalan Skt: SUCCEED IN SPAIN & .43 & .48 & .44 & .20 \\
\hline Catalan Skt: POLITICAL INTENTIONALITY & 2.54 & 2.61 & 2.60 & 2.10 \\
\hline Basque Skt: KNOWLEDGE & .61 & .55 & .70 & 1.00 \\
\hline Basque Skt: EVALUATION & 4.24 & 4.11 & 4.30 & 5.29 \\
\hline Basque Skt: ENJOYED YOUR REGION > SPAIN & .06 & -.08 & .60 & .57 \\
\hline Basque Skt: SUCCEED IN SPAIN & .65 & .63 & .70 & .71 \\
\hline Basque Skt: POLITICAL INTENTIONALITY & 2.11 & 2.10 & 1.80 & 2.71 \\
\hline
\end{tabular}

Knowledge (range from 0 to 1); Evaluation (range from 0 to 7); Enjoyed in your region more than in the rest of Spain (range from -1 to 1); Succeed in Spain (range from -1 to 1); Political Intentionality (range from 0 to 3). Source: DS1. 
However, there is a key point in the different appreciation of both sketches held by the neighbors of the two regions and the people who are more distant geographically. As we expected, appreciations of the Catalan and Basque sketches vary greatly amongst natives, neighbors and people who are geographically further away. The latter two categories (close neighbors and distant groups) are much more negative and tend to evaluate the contents of the Catalan and Basque sketches in a more aggressive and less self-mocking form. This explanation is to some extent logical if the results of the natives are compared with those of people who are geographically more distant from Catalonia and the Basque Country, in the south of the country, principally in Andalusia (SEV) and the Canary Islands (LZR). This is because their degree of familiarity with the sketch is lower, below the average, as the participants in the groups recognize (Catalan Sketch=.27; Basque Sketch=.55) and because cultural practices involving ethnic humor in the communities of the north of Spain, where Catalonia and the Basque Country are located, are often different from practices in the south of the country: participants from the south of Spain consider that Catalan and Basque ethnic humor will be a failure in their own regions (Catalan sketch=-.30; Basque sketch=-.08). However, it is much more interesting and surprising to consider the opinions of the neighboring communities of both the Catalans and the Basques, as there is a significant difference amongst them that should be noted. This difference, as we see in table 4, is important because the image held of Catalans and Basques throughout the country is to a large extent constructed through the relation between their neighbors and the people geographically distant.

Table 4. Types of humor in Catalan and Basque Sketches by proximity to Catalonia and the Basque Country of regional focus groups

\begin{tabular}{|c|c|c|c|c|c|c|}
\hline & \multicolumn{4}{|c|}{ PROXIMITY OF THE PARTICIPANTS } & \multirow[b]{2}{*}{$\mathrm{Chi}^{2}$} & \multirow[b]{2}{*}{$\mathrm{Chi}^{2}$} \\
\hline & SPAIN & Distant & Close & Native & & \\
\hline & $\%$ & $\%$ & $\%$ & $\%$ & (with natives) & (non natives) \\
\hline Catalan Skt: Balanced Humor (-) & 2.2 & 4.0 & 0.0 & 1.4 & $115.221^{* *}$ & $23.536^{*}$ \\
\hline Catalan Skt: Balanced Humor (n) & 1.1 & 2.0 & 0.0 & 0.7 & (gl 16) & (g| 8) \\
\hline Catalan Skt: Balanced Humor (+) & 34.4 & 34.5 & 38.9 & 29.3 & & \\
\hline Catalan Skt: Aggressive Humor (-) & 27.5 & 33.7 & 34.9 & 8.6 & $91.542^{* *}$ & 5.596 \\
\hline Catalan Skt: Aggressive Humor (n) & 1.1 & 1.2 & 0.7 & 1.4 & (Bal/Agg/SIf) & (Bal/Agg/Slf) \\
\hline Catalan Skt: Aggressive Humor (+) & 9.6 & 13.5 & 6.0 & 6.4 & & \\
\hline Catalan Skt: Self-Mocking Humor (-) & 4.1 & 0.8 & 5.4 & 8.6 & $23.820^{* *}$ & 1.775 \\
\hline Catalan Skt: Self-Mocking Humor ( $n$ ) & 1.7 & 0.4 & 0.7 & 5.0 & $(-n+)$ & $(-n+)$ \\
\hline Catalan Skt: Self-Mocking Humor (+) & 18.3 & 9.9 & 13.4 & 38.6 & & \\
\hline Basque Skt: Balanced Humor (-) & 8.8 & 11.3 & 7.9 & 2.3 & $66.990^{* *}$ & $34.619^{* *}$ \\
\hline Basque Skt: Balanced Humor ( $n$ ) & 1.7 & 1.5 & 1.3 & 2.3 & (gl 16) & (g|8) \\
\hline Basque Skt: Balanced Humor (+) & 21.4 & 22.3 & 31.6 & 12.9 & & \\
\hline Basque Skt: Aggressive Humor (-) & 16.5 & 21.7 & 10.5 & 4.5 & $48.314^{* *}$ & $17.717^{* *}$ \\
\hline Basque Skt: Aggressive Humor (n) & 0.8 & 1.0 & 0.0 & 0.8 & (Bal/Agg/SIf) & (Bal/Agg/Slf) \\
\hline Basque Skt: Aggressive Humor (+) & 6.8 & 6.6 & 3.9 & 9.1 & & \\
\hline Basque Skt: Self-Mocking Humor (-) & 2.7 & 2.6 & 2.6 & 3.0 & $36.628^{* *}$ & $13.916^{* *}$ \\
\hline Basque Skt: Self-Mocking Humor ( $n$ ) & 0.3 & 0.5 & 0.0 & 0.0 & $(-n+)$ & $(-n+)$ \\
\hline Basque Skt: Self-Mocking Humor (+) & 40.9 & 32.5 & 42.1 & 65.2 & & \\
\hline
\end{tabular}

Source: DS2.

It can be seen that the Catalan sketch is appreciated in a very similar way both by their neighbors -chiefly Aragonese (ZAR) and Valencians (VLN) - and by the more distant participants $\left(\mathrm{Chi}^{2}=5.596\right.$ according to the style of humor and $\mathrm{Chi}^{2}=1.775$ according to the positive and/or negative evaluations). This shows that the degree of familiarity of their neighbors does not seem to have a significant effect on the appreciation of their humor. In 
both cases the opinions on their perception of Catalan ethnic humor oscillates between considering it to be a positive, balanced type of humor (sophisticated, well elaborated, with original scripts) and a negative, aggressive type of humor (making fun of the other, the Spaniards). There is a greater appreciation of the self-mocking humor of the Catalans amongst their neighbors (13.4 per cent of their interventions) than amongst people more distant from Catalonia (9.9 per cent). It is rather important to notice that the neighboring communities of Catalans are very familiar with the ethnic issues that are the motive of the self-mocking humor in the sketch, such as Catalonia's bilingual particularity, as both the Aragonese and the Valencians share the same situation of bilingualism as Catalonia -this is not the same situation in case of Castilians (VLD), people from Madrid (MAD), Andalusians (SEV) or or Canary Islanders (LZR)-, although Aragonese and Valencians expressed this issue with different intensity and with different discourses than Catalans do. It is not surprising that there are high levels of appreciation of negative, aggressive humor between Catalan neighbors (34.9), exactly the same proportion as the geographically more remote participants (33.7).

Conversely, in the Basque case there is a totally different situation with respect to their neighbors: the latter consider that the Basque sketch has positive, self-mocking elements and is formally well constructed, while the perception of negative aggressiveness (making fun of the other, that is, of Spanishness) is much lower amongst their neighbors (10.5) than amongst participants who live further from the Basque Country (21.7). In fact, it might be suggested that the participants considered neighbors of the Basque Country -chiefly Galicians (ACÑ) and Castilians (VLD) -show a discourse of appreciation of the Basque sketch that is more similar to the Basques themselves than to the distant participants. Once again, it could be confirmed that the difference between the appreciation of the humor detected in the Basque sketch and in the Catalan sketch is more related to the content than to the form. In both cases the perception of balanced humor is high amongst their neighbors -very high in the case of the neighbors of the Basques- but the high levels of negative, aggressive humor appreciated in the case of the Catalans, against a lower level in the Basque case, would explain the different perceptions of the two ethnic minorities held in the country as a whole. It seems as if the Catalan sketch, unlike the Basque, was seen by most of the participants as a device used by a peripheral group for suspicious purposes -the behavior of a pretending center group who consider the Spaniards as a peripheral and incongruous one. In the Basque case, on the contrary, most of the participants, and especially their neighbors, admit that their ethnic sketch is really funny especially because they behave as a peripheral group who make fun at expense of themselves. Following Davies' model, it is confirmed that Basques and Catalans, like Scots and Jews, "are minorities, albeit in very different ways" (Davies 2002: 46). Maybe Basques are closer to what we refer above as the "Scottish" model: participants in our study consider Basques as a "minority or peripheral nation but similar to a larger national entity" (Davies 2002: 46) and, for this reason, they appreciated Basque ethnic humor because it is mainly based on making fun of their own group. On the contrary, Catalans are closer, but not completely, to the "Jewish" one: participants consider Catalan ethnic humor more balanced because [it] "mocks everything, both insiders and outsiders" (Davies 2002: 74), both Catalans and Spaniards. However, the discourses between the Spaniards about this sketch were strongly divided: some interventions stated this humor could be well-appreciated formally but there was also a lot of resistance to enjoying it.

The final hypothesis of this study concerns the possible direct influence of political reasons amongst the participants when appreciating Catalan and Basque ethnic humor. To this end we shall use the variable that measures the index of political intentionality of the two sketches, just as it was put to the participants in the focus groups through the questionnaire, and we shall compare it with the variables of evaluation of the sketches and the types of humor appreciated. In table 5 we found that there is a certain relation between the 
appreciation of political intentionality and evaluation: to the extent that there is an increase in the perception of political intentionality, there is a fall in the sketch's evaluation, appreciation at the regional level and possibilities of success, both in the Catalan case $\left(r^{2}=-.214\right)$ and in the Basque case $\left(\mathrm{r}^{2}=-.126\right)$. However, the correlations are low and not statistically significant.

Table 5. Appreciation of Catalan and Basque Sketches by perception of political intentionality

\begin{tabular}{|c|c|c|c|c|c|c|}
\hline & \multirow[b]{2}{*}{$\begin{array}{l}\text { SPAIN } \\
\text { Mean }\end{array}$} & \multicolumn{4}{|c|}{ POLITICAL INTENTIONALITY } & \multirow[b]{2}{*}{$\mathbf{R}^{2}$} \\
\hline & & $\begin{array}{l}\text { None } \\
\text { Mean }\end{array}$ & $\begin{array}{r}\text { Little } \\
\text { Mean }\end{array}$ & $\begin{array}{l}\text { Quite } \\
\text { Mean }\end{array}$ & $\begin{array}{l}\text { Much } \\
\text { Mean }\end{array}$ & \\
\hline Catalan Skt: EVALUATION & 4.34 & . & 5.33 & 4.54 & 4.12 & -.214 \\
\hline Catalan Skt: ENJOYED YOUR REGION > SPAIN & .05 & . & .50 & .04 & .00 & -.131 \\
\hline Catalan Skt: SUCCEED IN SPAIN & .43 & . & .33 & .58 & .37 & -.101 \\
\hline Basque Skt: EVALUATION & 4.24 & 6.00 & 4.13 & 4.11 & 4.19 & -.126 \\
\hline Basque Skt: ENJOYED YOUR REGION > SPAIN & .06 & .00 & .20 & .18 & -.09 & -.134 \\
\hline Basque Skt: SUCCEED IN SPAIN & .65 & 1.00 & .67 & .71 & .53 & -.203 \\
\hline
\end{tabular}

Evaluation (range from 0 to 7); Enjoyed in your region more than in the rest of Spain (range from -1 to 1); Succeed in Spain (range from -1 to 1). Source: DS1.

There are some explanations for that. Firstly, there is a limited variability in the codification of these questions, which means that it is difficult for a tendency to be significant, above all if the sample is not statistically large. Secondly, as we have shown throughout the study, the participants manage an extremely complex concept of evaluation in their discourses, including not only formal questions but also questions relating to the content of the sketches. That is why table 6 is interesting, as it shows the association between the variable of political intentionality and the codification of the three types of humor that we have used in this study. In table 6 we find that the variable of political intentionality has a certain significant association with appreciation of the humor, especially in the case of the Catalan sketch while not at all in the case of the Basque sketch.

Table 6. Types of humor of Catalan and Basque Sketches by perception of political intentionality

\begin{tabular}{|c|c|c|c|c|c|c|}
\hline & \multicolumn{5}{|c|}{ POLITICAL INTENTIONALITY } & \multirow{3}{*}{$\mathrm{Chi}^{2}$} \\
\hline & SPAIN & None & Few & Quite & Much & \\
\hline & $\%$ & $\%$ & $\%$ & $\%$ & $\%$ & \\
\hline Catalan Skt: Balanced Humor (-) & 2.2 & 0.0 & 2.7 & 2.5 & 2.0 & $37.441^{* *}$ \\
\hline Catalan Skt: Balanced Humor (n) & 1.1 & 0.0 & 1.4 & 1.7 & 0.9 & (gf 16) \\
\hline Catalan Skt: Balanced Humor (+) & 34.4 & 0.0 & 30.1 & 35.8 & 34.8 & \\
\hline Catalan Skt: Aggressive Humor (-) & 27.5 & 0.0 & 16.4 & 25.8 & 30.5 & $25.936^{* *}$ \\
\hline Catalan Skt: Aggressive Humor (n) & 1.1 & 0.0 & 1.4 & 1.7 & 0.9 & (Bal/Agg/Slf) \\
\hline Catalan Skt: Aggressive Humor (+) & 9.6 & 0.0 & 2.7 & 17.5 & 8.3 & \\
\hline Catalan Skt: Self-Mocking Humor (-) & 4.1 & 0.0 & 6.8 & 2.5 & 4.0 & 5.812 \\
\hline Catalan Skt: Self-Mocking Humor (n) & 1.7 & 0.0 & 4.1 & 1.7 & 1.1 & $(-n+)$ \\
\hline Catalan Skt: Self-Mocking Humor (+) & 18.3 & 0.0 & 34.2 & 10.8 & 17.5 & \\
\hline
\end{tabular}




\begin{tabular}{|c|c|c|c|c|c|c|}
\hline Basque Skt: Balanced Humor (-) & 8.8 & 11.1 & 10.7 & 6.4 & 9.8 & 36.205 \\
\hline Basque Skt: Balanced Humor (n) & 1.7 & 0.0 & 1.9 & 2.0 & 1.5 & (gf 24) \\
\hline Basque Skt: Balanced Humor (+) & 21.4 & 37.0 & 26.2 & 25.0 & 15.1 & \\
\hline Basque Skt: Aggressive Humor (-) & 16.5 & 7.4 & 17.5 & 10.3 & 21.9 & 16.342 \\
\hline Basque Skt: Aggressive Humor (n) & 0.8 & 0.0 & 1.9 & 1.0 & 0.4 & (Bal/Agg/Slf) \\
\hline Basque Skt: Aggressive Humor (+) & 6.8 & 3.7 & 8.7 & 7.8 & 5.7 & \\
\hline Basque Skt: Self-Mocking Humor (-) & 2.7 & 3.7 & 1.0 & 2.9 & 3.0 & 16.207 \\
\hline Basque Skt: Self-Mocking Humor (n) & 0.3 & 0.0 & 0.0 & 1.0 & 0.0 & $(-n+)$ \\
\hline Basque Skt: Self-Mocking Humor (+) & 40.9 & 37.0 & 32.0 & 43.6 & 42.6 & \\
\hline
\end{tabular}

Source: DS2.

The indices of association indicate that, in the Catalan case, the perception of a greater political intentionality is related to a considerable increase in the perception of aggressive humor (negative but also positive) and an equally considerable fall in the appreciation of positive, self-mocking humor. Perhaps the decrease in the number of interventions that speak of positive self-mocking humor is the most relevant fact: 34.2 per cent of interventions that see little intentionality against 17.5 per cent that see a lot of intentionality. It is evident that, in the case of the sketch of Catalan ethnic humor, the interventions that comment on the content contain discourses that are different according to the political intentionality detected in the sketch $\left(\mathrm{Chi}^{2}=25,936^{* *}\right)$, but the influence of the political background of the participants should be borne in mind. The fact is that the increase in the perception of aggressiveness is neither lineal nor homogeneous but divided instead: some people have positive appreciations of the aggressiveness of the Catalan sketch while others have negative appreciations. As we saw in table 2, in some cases there are increases in the negative perception of aggressiveness, basically in groups like Andalusia (SEV), Madrid (MAD) or Valencia (VLN), where opposition to the peripheral nationalist discourse of the Catalans is strong. However, in other cases there are increases in the positive appreciation of the aggressiveness of the Catalan sketch, especially in groups like the Basques (BIO), Galicians (ACN) or Canary Islanders (LZR), where support for satirical discourses based on the peripheral nationalist perspective is much more relevant. In any case, it is very interesting to observe that the percentage of interventions describing the form of the Catalan humoristic sketch as a positive balanced type of humor remains constant and with very high percentages, between 30.1 and 35.8 per cent, independent of the political intentionality appreciated in that sketch. On the other hand, it should be noted that the appreciation of the Catalan sketch is also very balanced between negative and positive affirmations: this finds reflection in the fact that the difference between positive, neutral and negative appreciations is not statistically significant $\left(\mathrm{Chi}^{2}=5.812\right)$. In short, the association between intentionality and styles of humor is fairly evident in the Catalan case, especially with respect to the content of the sketch, where changes of opinion are much more disparate, but it is possible that the constant high appreciation of the form of the sketch reduces this association.

On the contrary, in the case of the Basque sketch the association of the variable of political intentionality and the discourses on styles of humor is ruled out. Although it is true that the increase in the perception of political intentionality affects the reduction of the number of interventions stressing the balanced character of this sketch's humor (37.0 per cent of interventions in the people who see no political intentionality against 15.1 of interventions amongst the participants who see a lot of intentionality), the rest of the categories undergo few changes and, besides, they are not lineal. Thus, for example, amongst the people who see a lot of political intentionality there is an increase in the affirmations of negative, aggressive humor but also in the affirmations of positive, self-mocking humor. The final result is that the 
more or less politicized appreciation of this sketch does not significantly alter the distribution of the participants' arguments towards a concrete style of humor (40 per cent self-mocking; 25 per cent aggressive and 35 per cent balanced), independent of the political intentionality that the participants might detect.

\section{Conclusions}

In a debate with professional humorists, held on Spanish public television in 6 May 2011 to discuss the supposed importance and function of humor, one of the country's most famous cartoonists stated in an emphatic tone that Basque public television's program Vaya semanita, from which we extracted the ethnic humor sketch for this study, "was the most important event that had been made in the Basque Country since 1975 to achieve coexistence in the country, unlike the work of the politicians for years and years" (sic). While it is true that societies, or Spanish society at least, do not always give humorists the recognition they possibly merit, I think this affirmation tries to place a political responsibility onto the shoulders of humor that it is far from being able to meet. At the same time, it underrates the practical and systematic work that many other people, anonymous and not so anonymous, have done and are doing on a daily basis, often placing their lives at risk, carrying out physical tasks with visible results so as to guarantee political coexistence in the Basque Country. It is possible that somebody believes that the task of a humorous program like Vaya semanita, making fun at the expense of their own Basques, is important in a process of putting an end to terrorist activity, but there is little or no empirical evidence to support this claim.

The aim of this study has been to analyze how and to what extent ethnic humor made in two specific Spanish peripheral regions, as Catalonia and Basque Country, was appreciated in the whole country. The basic question was to ascertain how the Spanish public would react and what discourses it would articulate when the aim of the ethnic humor of Basques and Catalans was not only to be self-mocking, as peripheral groups that are comically incongruent with respect to Spanishness, but also made fun of other social groups identified with the center, i.e. with the Spanish social majority, which is supposedly more congruent with itself. In analyzing the data we found that the discourses on the appreciation of the Catalan and Basque sketches in the different focus groups around Spain were very varied, and the arguments used were evenly divided amongst three big ideal types of humor: balanced humor, aggressive humor and self-mocking humor. Perhaps the first great difference was between the positive and negative opinions in the groups about this kind of ethnic humor, as we saw in table 2. On one side, we could find groups whose participants appreciated this type of ethnic humor with more positive than negative interventions, like Basques (BIO), Canary Islanders (LZR) Galicians (ACN), and Catalans (BCN1). It is not accidental that in all these regions there are popular television programs on ethnic humor. In this side it is included the group of Spanish immigrants in Catalonia (BCN2), who identify with a more incongruent position with respect to the idea of the center in Spain: people who felt that their Spanish identity is to some extent a minority position in a particular region of Spain. People in group BCN2, coming from some Spanish regions and living in Catalonia, recognized immediately the comic incongruences in both sketches because the topics involved were familiar to their own experiences and enjoyed because of that familiarity. On the other side, we could find groups where this type of humor is not appreciated because, amongst other reasons, they identify with the more congruent position that emerges of the center's identity in Spain, like people from Madrid (MAD) and Castilla (VLD), who strongly rejected the Catalan sketch (-42.1 and -42.9) or even people from Valencia (VLN), who rejected the Basque sketch (-37.2), as we 
see in table 2. Those participants identified with the positions of the center generally reacted with the argument that this type of ethnic humor is very boring, rather aggressive, or that they can't understand how people can enjoy it through programs that have been broadcast for many years on the autonomous televisions channels of these regions. Obviously, it would be simplistic to say these people lack a sense of ethnic humor, but perhaps the absence of a feeling of incongruence on ethnic questions at the Spanish level reduces the possibilities of such humor being appreciated. Besides, it is not accidental that in these three regions there are no television programs of this kind of ethnic humor.

Apart from this consideration, with respect to the balanced humor that we have made to coincide with appreciation of humor based on formal elements, it must be said that both the Catalan sketch and the Basque sketch received highly positive appreciations, which were slightly higher in the Catalan case. Numerous interventions in the groups stressed the high degree of sophistication of the sketches, their good scripts, their careful staging, the use of word games and numerous well-elaborated cognitive incongruities. However, when it came to evaluating the content of the sketches, the discourses were very different in the two cases. In the case of the Basque sketch, there was a greater prevalence amongst participants to appreciate its self-mocking elements, especially amongst the communities in the north of Spain, and even the participants chosen to represent the majority positions of the center of the country. They confirmed that Basque ethnic humor is a type of peripheral humor that is appreciated, and that it can be appreciated in the country as a whole. Conversely, in the case of the Catalan sketch, the high perception of negative aggressive elements resulted in this sketch encountering critical evaluations and resistance in numerous interventions, not only amongst the participants identified with the majority positions of the center of the country but even amongst other peripheral groups neighboring on Catalonia. These interventions, although they recognized the self-mocking character of Catalan humor, showed considerable suspicion or distrust towards this type of humoristic practice, especially because of the high perception that Catalan humor consists in making fun of Spanishness. The position of Basques and Catalans towards their own sketches to some extent confirmed the view of the country as a whole: the Basques participating in the group considered that their sketch could be successful in Spain, while the Catalans were much more doubtful about the possibilities of their sketch succeeding in the country as a whole. In case of Basques, the perception of their own sketch is similar to the rest of the Spaniards: all of them appreciated high level of selfmocking in the sketch. Nevertheless, in case of Catalans the situation is diferent: Catalans themselves appreciate the high level of self-mocking in their sketch, but the rest of the groups appreciated that this sketch is highly balanced but rather aggressive. Following the Davies' studies comparing the more self-mocking ("Scottish" model) or more balanced ("Jewish" model) ethnic humor, our study confirms the differences between them and offers an interesting analogy to the Spanish case. Many of the explanations made by Davies in his works about the self-mocking Scottish sense of humor (Davies 2002: 17-49) could easily be used to understand the Basque case. However, his description of the balanced Jewish sense of humor (Davies 2002: 51-75) could be used to analyze the Catalan case but with some caution due to the high level of resistance in many Spanish participants of our study to enjoying the Catalan sense of humor. Our impression is that the result of our study, in this point, says more about the participants -the perception of aggressiveness in this sketch is based on the problematic relation between Catalans and the rest of Spaniards- than about the sketch in itself.

Finally, there was one last question that we wished to explore and that has to do with the possible relation between ethnic humor and politics in Spain. The fact that both sketches could be interpreted due to their potential political intentionality, which the majority of the participants in the focus groups recognized as high, was a good yardstick for measuring the 
possible effect of the political variant on the appreciation of this type of ethnic humor of Catalans and Basques. The result, very different in the two cases, minimizes this supposed connection between appreciation of humor and politics but without eliminating it completely. In the Basque case we saw that the fact of participants detecting greater or lesser political intentionality in the sketch had no significant influence when it came to arguing about its humoristic virtues. The reason is that, in spite of the more or less aggressive character that Basque political activity might exhibit and that a large part of public opinion in Spain more or less explicitly rejects identity and nationalist questions in the Basque Country, the majority of the interventions argued that the sketch dealt with an ethnic group that basically laughs at itself with more or less success; that is, beyond political questions, Basques' humorous behavior is according to what is expected from a peripheral group such as they are. In fact, the Basques themselves basically confirm this appreciation of their humor being essentially selfmocking.

In the Catalan case, however, political intentionality served to confirm that the perception of this type of humor in Spain in general gives rise to greater distrust and suspicion, in spite of many participants recognizing that in formal terms this humor is well elaborated and that there are humoristic conditions for enjoying it. For a large part of the interventions, the idea that what is to be found behind negative aggressive humor is a minority, which wishes to make fun of majority could decrease the appreciation of this humor. In this respect it was interesting to find that in the focus group formed in Catalonia with Spanish immigrants proceeding from different areas the arguments were that Catalan ethnic humor is highly sophisticated (positive balanced humor) but with a high dose of negative aggressive humor, which seeks to laugh at Spanishness. Certainly, this image contrasted sharply with the idea that native Catalans have of their own sketch, which they largely considered to be positive, balanced and self-mocking but not aggressive.

In sum, the comparison between Basques and Catalans -both incongruent with respect to Spain but whose humoristic productions are appreciated differently- shows that we should not be thinking about what can be done by peripheral ethnic humor to change a country socially and politically. Instead, we should be asking what the reasons are for a country recognizing this peripheral humor in one way or another. Generally, the political reasons that influence the appreciation of humor often lie outside humor itself, and are more related to (pre)political predispositions, attitudes and prejudices than to the characteristics of humor as such (Davies 1998c: 75-96). In these cases, humor can at times also help to detect these symptoms.

\section{Notes}

[1] The trilogy by Christie Davies $(1990,1998$ a, 2002) is probably the most comprehensive analysis about ethnic humor in international comparative perspective. In these three books the mentions of ethnic humor in Spain are brief (1990: 11-12; 1998a: 2-3; 2008: 164) but well documented. I have talked several times with Professor Davies about this topic and I am very convinced about his broad background about Spanish ethnic humor. As for this paper, nevertheless, I recognize my surprise because in Davies' works he always quotes the Catalan case as a persistent "canny group" in ethnic jokes in Spain, but he did not make any comment on the Basque one. My impression is that Davies considers -correctly, in my view- that Catalans and Basques symbolize two different patterns of ethnicity related to the Spanish identity, one closer to the Spaniards (Basques) than the other (Catalans). In fact, the aim of the study is to test to what extent Catalans and Basques are two ethnic groups that, in spite of their shared feeling of love/hate about the Spanish national identity, have a different relationship with the Spaniards and this difference could affect the humor appreciation of the Spaniards. 
[2] The name of the Catalan television program, Polonia (Poland), from the outset indicates its selfparodying character. For a long time in Spain the Catalans were known as "Poles". Although there is no consensus on the origin of this kind of nickname, the intention was clearly to make fun of the Catalans and in a certain way to look down on their differences, thus expressing that the Spanish as a whole considered the Catalans to be a different ethnic group, speaking a language other than Spanish, and separated by a certain emotional distance. It seems the choice of "Poland" was a chance occurrence, perhaps the Poles were an ethnic group that was the butt of humor in other countries and they sufficiently reflected a certain distance from Spanishness. At present, thanks to this television program, the Catalans use the expression "Pole" as a form of creative self-mocking pride.

[3] In this study, when "aggressive humor" is mentioned it is important to note that here aggressiveness is considered something totally different from any kind of physical aggression. As many humor scholars have pointed out, aggressive humor in humor is play with the aggression as a comic device that shows the existence of some incongruities that make us laugh. As we will se in this study, "aggressive humor" can be socially appreciated in different ways, either positive or negative.

[4] The example of stupid jokes about Irish people in the United States in which allusion is made to the supposed "dirtiness" of this ethnic group, unlike the stupid jokes about this ethnic group in Great Britain, where allusions to dirtiness do not appear, as studied by Davies, is a perfect example for expressing this idea. The difference between the two cases does not mean that in one country this ethnic group is more or less clean than in the other country, but instead shows the difference existing in these two societies about what is considered normal from the hygienic point of view and what is considered to be incongruent and, therefore, the object of humor (Davies 1998b).

[5] There is ethnic humor belonging to other Spanish peripheral groups; mainly the following four: Andalusians, Canary Islanders, Galicians and Aragonese. In all these cases we find the reproduction of situations that are fairly similar to the Catalan and Basque cases, insofar as the local ethnic features of these groups have some type of particularity that is striking, i.e. comically incongruent, in comparison to what could be considered "normal Spanishness". We will return to this question when we explain the reasons for selecting the sample in our case study.

[6] The choice of the sketches used for the purposes of the study was quite difficult because participants would have to recognize three possible ideal-types of appreciation of humor (balanced, aggressive and self-mocking) in each sketch. We thought that Catalan and Basque sketches should be simple and as vary as possible in order to in order to easily detect these three appreciations. We assumed that the prevalence of one or another ideal-type of appreciation depends on the participants more than the humor practice in itself.

[7] The cities in the simple are: Bilbao=BIO (the Basque Country); Seville=SEV (Andalusia); Madrid=MAD, the capital of Spain; Barcelona $=\mathrm{BCN}$ (Catalonia), Valencia $=\mathrm{VLN}$; Zaragoza=ZAR (Aragon); Lanzarote=LZR (the Canary Islands); Valladolid=VLD (Castilla and Leon) and A Coruña=ACN (Galicia). A focus group was held in all the cities except in Barcelona where two were held: one with people born in Catalonia (BCN1) and another group with Spaniards who had not been born in Catalonia but who had been living in Catalonia for many years, proceeding from different autonomous communities in Spain (North, center and South) and who had a perfect knowledge of the Catalan language and culture (BCN2).

[8] Both sketches can be found on the Internet:

In the Catalan case (http://www.youtube.com/watch?v=URCeQwPe9qQ\&NR=1)

In the Basque case (http://www.youtube.com/watch?v=NUR51RDIELQ\&feature=related).

[9] The "negative" or "positive" codification is not related to what the researcher thinks but to what the participants said about the sketches and the issues that led to their interventions.

[10] The coding of this variable was made as follows: we select the "aggressive" and "self-mocking" categories when participants mentioned specifically the butt of the joke as the main feature of the humor practice, and select the "balance" category when participants focus their attention on the form and structure of the sketch.

[11] I wish to thank Begoña Freire and Iker Borrondo for their work and for their commitment throughout the learning process and in the fruitful discussions we held over several months in order to codify the qualitative variables and about the design of the study. 


\section{References}

Attardo, S. (1994). Linguistic theories of humor. Berlín \& Nueva York: Mouton de Gruyter.

Attardo, S., \& Raskin, V. (1991). 'Script theory revis(it)ed: Joke similarity and joke representation model'. Humor. International Journal of Humor Research, 4(3-4), 293-348.

Carr, R., \& Fusi, J. P. (1981). Spain. Dictatorship to Democracy. London: Harper Collins Publishers.

Castello, E. (2007). 'The production of television fiction and nation building. The Catalan case'. European Journal of Communication, 22(1), 49-68.

Davies, C. (1990). Ethnic humor around the world: A comparative analysis. Bloomington: Indiana University Press.

Davies, C. (1998a). Jokes and their relation to society. Berlin: Mouton de Gruyter.

Davies, C. (1998b). 'Ethnic jokes about alcohol: A study of the humour of ambivalence', In C. Davies (Ed.), Jokes and their relation to society, Berlin: Mouton de Gruyter, pp. 101-136.

Davies, C. (1998c). 'Jewish jokes, anti-semitic jokes and hebredonian jokes', In A. Ziv (Ed.), Jewish humor, New Brunswich NJ: Transaction Publishers, pp. 75-96.

Davies, C. (2002). The Mirth of Nations. New Brunswich NJ: Transaction Publishers.

Davies, C. (2008). 'Undertaking the comparative study of humor', In V. Raskin (Ed.), The primer of humor research, Berlin: Mouton de Gruyter, pp. 157-182.

Diez Medrano, J. (1995). Divided nations. Class, politics and nationalism in the Basque Country and Catalonia. New York: Cornell University Press.

Ferguson, M. A., \& Ford, T. E. (2008). 'Disparagement humor: A theoretical and empirical review of psychoanalytic, superiority, and social identity theories'. Humor. International Journal of Humor Research, 21(3), 283-312.

Ford, T. E., \& Ferguson, M. A. (2004). 'Social consequences of disparagement humor: A prejudice norm theory'. Personality and Social Psychology Review, 8(1), 79-94.

Grotjahn, M. (1987). 'Dynamics of jewish jokes'. American Behavioral Scientist, 30(3), 96-99.

Gruner, C. R. (1997). The game of humor. A comprehensive theory of why we laugh. New Brunswich NJ: Transaction Publishers.

Kasmir, S. (2002). 'More basque than you: Class, youth, and identity in an industrial Basque town'. Identities: Global Studies in Culture and Power, 9, 39-48.

Kuipers, G. (2001). Good humor, bad taste. A sociology of the joke. Berlin: Mouton de Gruyter.

Kuipers, G. (2008). 'The sociology of humor', In V. Raskin (Ed.), The primer of humor research, Berlin: Mouton de Gruyter, pp. 361-398.

Linz, J. J. (1993). 'State building and nation building'. European Review, 4(1), 355-369.

Martin, R. A. (2007). 'Personality approaches to the sense of humor'. In R. A. Martin (Ed.), The psychology of humor. An intrepretative approach, California: Elsevier Academic Press, pp. 191-228.

Martin, R. A., Puhlik-Doris, P., Larsen, G., Gray, J., \& Weir, K. (2003). 'Individual differences in uses of humor and their relation to psychological well-being: Development of the humor styles questionnaire'. Journal of Research in Personality, 37, 48-75.

Preston, P. (1986). The triumph of Democracy in Spain. London: Routledge.

Preston, P. (2012). The Spanish Holocaust. London: Harper Collins Publishers.

Raskin, V. (1985). Semantic Mechanisms of humor. Hingham: Reidel Publishing Company.

Ruch, W. (1992). 'Assessment of appreciation of humor: Studies with the 3 WD humor test', In C. D. Spielberg, \& J. N. Butcher (Eds.), Advances in personality assessment. vol.9, Hillsdale NJ: Lawrence Erlbaum Associates, pp. 27-75.

Ruch, W. (1996). Measurement approaches to the sense of humor. Berlin: Mouton de Gruyter.

Ruch, W., \& Forabosco, G. (1996). 'A cross-cultural study of humor appreciation: Italy and Germany'. Humor. International Journal of Humor Research, 9(1), 1-18.

Ruch, W., Ott, C., Accoce, J., \& Bariaud, F. (1991). 'Cross-national comparison of humor categories: France and Germany'. Humor. International Journal of Humor Research, 4(3-4), 391-414.

Ziv, A. (1988). National styles of humor. New York: Greenwood Press. 